\title{
Pronera no Sertão Mineiro Goiano: Reflexões sobre emancipação social e Educação do Campo
}

\author{
Maria da Conceição da Silva Freitas ${ }^{1}$, Cláudia Valéria de Assis Dansa ${ }^{2}$, Joice Marielle da Costa Moreira ${ }^{3}$ \\ ${ }^{1}$ Universidade de Brasília - UnB, Departamento de Teoria e Fundamentos. Faculdade de Educação, Campus \\ Universitário Darcy Ribeiro - TEF - Asa Norte - Brasília - DF. Brasil. mcsilva@unb.br. Universidade de Brasília \\ - UnB. ${ }^{3}$ Universidade de Brasília - UnB.
}

RESUMO. Assentados da Reforma Agrária de baixa escolarização buscam inclusão social na escola. Como desenvolver projeto pedagógico para atender sujeitos do campo com suas demandas específicas numa perspectiva emancipatória? Os objetivos foram refletir sobre: a Educação do Campo como resultado das lutas dos movimentos sociais pelo direito dos sujeitos do campo de pensar a educação e a produção a partir do lugar onde vivem, tendo como horizonte a emancipação humana; e, a complexidade da formação de educadores na educação de adultos. Adotou-se a metodologia da reinvenção democrática para a formação de sujeitos ativos, com diferentes saberes, capazes de resolver problemas e participar da gestão. Os resultados apontam o rompimento com resistências da educação tradicional via atividades participativas cuidadosamente elaboradas pelos educadores; sistematização interdisciplinar de conceitos integradores como identidade e territorialidade; conquista da autonomia no cotidiano pelos alfabetizados. Os aportes teóricos da Educação do Campo trouxeram novas abordagens teórico-metodológicas para o atendimento às demandas educacionais dos sujeitos excluídos. Conclui-se que a perspectiva emancipatória contribuiu para a construção colegiada dos processos possibilitando aos educandos romper com a dependência de intermediários. Embora a resolução de problemas imediatos não garanta um salto social e político emancipatório, fortalece o diálogo para empoderamento em novos espaços.

Palavras-chave: Políticas Públicas de Reforma Agrária, Educação do Campo, Emancipação, Formação de Educadores, Educação de Jovens e Adultos. 


\title{
Pronera in the Brazilian Backwoods - Minas/Goiás: Reflexions about social emancipation and Rural Education
}

\begin{abstract}
Settlers of Agrarian Reform with lower education search for social inclusion through school. How develop pedagogic project to attend them according to their specific demands, in an emancipator way? The study objectives were reflections on: Rural Education as a result of the struggle of social movements for the settlers' rights of perceiving education and production through the land where they live, having their own emancipation in mind and the complexity in training educators for Adults Education. A methodology of democratic reinvention was adopted to form active people, with diverse knowledge, able to solve problems and participate in managing. The results point to rupture traditional education methods by participatory activities carefully elaborated by teachers; Adopting interdisciplinary systems integrating concepts such as identity and territoriality into school subjects; The conquest of autonomy on day-to-day life to the literate. The theoretical contributions from Rural Education have brought new approaches to theories and methodologies in meeting the educational demands. In conclusion, the emancipatory perspective contributed for the schooled construction of the processes that allowed settlers to break up with dependency of intermediaries. Although the resolution of immediate problems does not guarantee social and political leap, it strengthens dialog and empowerment in new relational spaces.
\end{abstract}

Keywords: Public Policies of Rural Reform, Rural Education, Emancipation, Adults Education, Training Educators. 


\section{Pronera en la región del Sertão Minero-Goiano: Reflexiones con respecto a la emancipación social y la Educación del Campo.}

RESUMEN. Personas de asentamientos de Reforma Agraria con baja escolarización buscan inclusión social a través de la escuela. ¿Cómo desarrollar proyectos pedagógicos para personas del campo con sus demandas desde una perspectiva emancipadora? Los objetivos propuestos reflexionan: Educación del campo como resultado de luchas de movimientos sociales por el derecho de pensar la educación y la producción desde del lugar en donde viven, teniendo como horizonte la emancipación humana; y, la complejidad de la formación de educadores en la educación de adultos. Fue adoptada metodología de reinvención democrática para la formación de individuos activos, en la gestión y capaces de resolver problemas. Los resultados apuntan ruptura con las resistencias de la educación tradicional a través de actividades participativas; sistematización interdisciplinar de conceptos integradores identidad y territorialidad; conquista de autonomía de lo cotidiano por los alfabetizados. Las contribuciones teóricas trajeron perspectivas teórico-metodológicas para la atención de las demandas educativas de los excluidos. Conclusión: la perspectiva emancipadora contribuyó a la construcción colegiada de los procesos, permitiendo a los educandos romper con la dependencia de intermediarios. Aun cuando la solución de problemas inmediatos no garantiza un salto social y político de carácter emancipador, si fortalece el diálogo para el empoderamiento de nuevos espacios relacionales.

Palabras clave: Políticas Públicas de Reforma Agraria, Educación del Campo, Educación de Adultos, Formación de Educadores, Emancipación. 


\section{Introdução}

Ao visitar uma das salas de aula do projeto TeCiCampo perguntamos aos Educandos por que eles queriam se alfabetizar e escolarizar. Um senhor dos seus setenta anos contou que, quando mais jovem, foi ao caixa de um banco retirar dinheiro que havia ganho. Ao receber, embora não soubesse a matemática oficial, olhou para a quantidade de notas e percebeu que estava faltando uma quantia. O caixa respondeu, com muito desrespeito que, sendo analfabeto, ele não sabia contar, que a quantia estava correta; portanto, ele deveria ir embora, pois, ninguém ali acreditaria nele. Homem maduro, ele foi atrás do gerente que percebeu a malandragem do caixa e fez com que nosso educando recebesse o que era dele por direito. Assim como este, muitos outros relatos nos deram a dimensão dos problemas enfrentados por estes sujeitos e o horizonte da necessidade e expectativa da transformação desta situação por meio da educação.

O que incomoda essas pessoas é o tratamento agressivo e jocoso que a sociedade lhes reserva, assim como a ausência de valor social que acompanha sua condição e a exclusão de processos que exigem a leitura e a escrita. Muitos têm um brilho especial, são alegres, inteligentes, se destacam no ambiente. Alguns ocultam, outros não, as dificuldades para realizar tarefas corriqueiras como pagar contas, receber a aposentadoria, decifrar o nome de um ônibus na parada, confirmar se o troco no supermercado está certo.

O que propomos neste texto é relatar a experiência de Educação de Jovens e Adultos do Programa Nacional de Educação na Reforma Agrária (Pronera), por nós vivida no Sertão Mineiro Goiano, no período de 2012 a 2014, e refletir sobre como desenvolver um projeto pedagógico com vistas a atender a demanda desses sujeitos de aprendizagem que são os adultos do campo com suas especificidades, trabalhando numa perspectiva emancipatória. Quem são os sujeitos envolvidos neste processo e as possibilidades e desafios encontrados no percurso.

\section{A Educação do Campo}

A Educação do Campo nasce a partir da luta dos movimentos sociais camponeses pelo direito a um processo educativo que leve em consideração suas especificidades e demandas. Isto significa, como aponta Fernandes (2004 p. 141), “... defender o direito que uma população tem de pensar a educação a partir do lugar onde vive...", de seu vínculo a um projeto de sociedade e desenvolvimento e às lutas 
sociais. Não há como pensar a Educação do Campo sem considerar a diversidade de sujeitos que fazem dele, mais que um espaço geográfico, um espaço de vida com sua cultura, seus projetos e suas lutas. Segundo Caldart (2012 p. 260) a Educação do Campo “... não é para nem apenas com, mas sim, dos camponeses, expressão legítima de uma pedagogia do oprimido. Combina luta pela educação com luta pela terra, pela Reforma Agrária, pelo direito ao trabalho, à cultura, à soberania alimentar, ao território."

Como afirma a mesma autora (2012 p. 260), o objetivo da educação do campo e seus sujeitos a remetem às questões do trabalho, da cultura, do conhecimento e das lutas sociais dos camponeses e ao embate (de classe) entre projetos de campo e entre lógicas de agricultura, que tem implicações no projeto de país e de sociedade e nas concepções de política pública, de educação e de formação humana.

$$
\text { Molina e Sá (2012, p. 325) }
$$
consideram que o papel contrahegemônico da escola do campo está em formular e executar um projeto de educação integrado a um projeto político de transformação social liderado pela classe trabalhadora. Ou seja, embora se organize em torno do acesso à escola, a Educação do Campo trata de lutas contrahegemônicas, na perspectiva de práxis, reafirmando a concepção emancipatória. Seus sujeitos tem exercitado o direto de pensar a pedagogia desde a sua realidade específica, mas, não visando somente a si mesmos: a totalidade lhes importa, e é mais ampla do que a pedagogia, evidenciando a indissociabilidade entre a Educação do Campo e a luta dos camponeses por projetos sociais contra a exclusão, e por modelos produtivos que visem à emancipação humana e uma nova construção das relações sociedadenatureza.

\section{EJA no campo}

Os problemas da EJA no campo são enormes. A educação rural no Brasil frequentemente trabalhou na perspectiva de importar para o campo um modelo urbano, que nada mais fez do que estimular parte desta população a deixar o campo ou a escola. Parte deste ensino urbano passou a reforçar a desqualificação do camponês, representando o campo, no imaginário popular, como local de atraso em relação ao novo sistema industrial capitalista que se implantava, estimulando o êxodo rural, das mulheres e, especialmente, da juventude.

Na verdade, o que se constata é que a instrução dada através da escola pode subtrair o filho do camponês de seu meio. Os jovens escolarizados já não entendem, ou têm vergonha de dizer 
que entendem a linguagem da terra, das plantas, dos ventos e da chuva, já não se sentam à vontade em volta do fogão à lenha contando e ouvindo histórias dos antigos, mas também não ficam à vontade na cidade, são os deslocados, são os sem-lugar. (Ribeiro, 2012, p. 9).

As condições de camponês e de analfabeto dificultam a relação com instituições como bancos, órgãos públicos, estabelecimentos comerciais tornando-os vulneráveis e expostos à humilhação, e ao descrédito. Além disto, os documentos, contratos, boletos e outros materiais escritos com que tem de lidar fazem com que necessitem permanentemente da ajuda de um outro para se situar, sendo a família a mais demandada para tal. Também sua contribuição aos movimentos fica, muitas vezes, limitada ao cumprimento de tarefas e resposta a comandos da liderança, necessitando de apoio para compreender e implementar a dimensão reflexiva e estratégica das lutas e também para internalizar o sentido de pertencimento e solidariedade ao movimento, por exemplo, após estar assentado.

Estudar é uma demanda das mais sérias e importantes da população analfabeta ou semi alfabetizada do campo. Isto não significa que havendo a abertura de salas de aula, estes terão, automaticamente, condições, disposição ou mesmo motivação para permanecer no processo escolar. Outros fatores interferem: saúde, meios de chegar à escola no dia a dia e, se a escola, finalmente, poderá atender às demandas reais da sua vida cotidiana ou se continuará sendo um espaço sem significação para quem quer permanecer no campo. Também dependerá dos métodos de ensino e das condições como os/as educadoras/es atuam junto aos Educandos/as, pois, estes já são adultos, muitos idosos e consideram difícil aprender, como se pode perceber na expressão ouvida com frequência: "Papagaio velho não aprende a falar". Muitos, ainda, sentem que merecem respeito e, se não o tem, evadem.

\section{A Emancipação Social}

Conforme Ribeiro (2012, p. 300), os conceitos de cidadania, tanto grega quanto burguesa, partem de uma construção elitista que exclui os trabalhadores. Em contrapartida, temos hoje os movimentos sociais propondo a construção de uma cidadania que rompe com este conceito excludente trazendo para dentro dela os sujeitos trabalhadores em movimento.

Neste sentido, os conteúdos que definem a história e a materialidade da cidadania atual são incompatíveis com a maioria da população, em particular com os sujeitos políticos coletivos que constituem o movimento camponês. Isso porque a cidade é o núcleo econômico- 
político incrustado no processo de constituição da cidadania, tanto grega quando moderna, definindo, por sua vez, a cultura que expressa a civilização e, sobretudo, o perfil urbano da educação moderna sob controle do Estado. Entretanto, é possível pensar a emancipação projetada pelas classes subalternas ao confrontar a cidadania como invenção, tanto dos proprietários gregos quanto dos burgueses, com o horizonte de libertação para o qual caminham os movimentos sociais populares, entre eles o movimento camponês, e sua proposta de Educação do Campo.

Para Paulo Freire (1978 e 2003 como citado em Ribeiro, 2012 p. 302) a libertação não se dá como uma tomada de consciência isolada da injustiça das relações sociais capitalistas, mas, essencialmente, numa práxis datada e situada, que tem por sujeitos os povos oprimidos. Assim como Dussel, pesquisador mexicano, autor de "Ética da libertação" (2012 como citado em Ribeiro, 2012, pp. 301-302) e Rebellato (2000 como citado em Ribeiro, 2012, pp. 301302), uruguaio que propõe uma ética da autonomia através da crença nas nossas próprias forças, todos pensam a emancipação como projeto e ação coletivos das vítimas, dos excluídos, dos desumanizados.
Marx e Engels (como citado em Ribeiro 2012, p. 302) tem a classe revolucionária como autora de tal projeto e ação: para além da liberdade e da autonomia individuais implícitas na cidadania, a classe revolucionária, no seu processo de construção, coloca como horizonte a emancipação de toda a humanidade, uma emancipação social do trabalho alienado e da propriedade privada dos meios de produção - incluindo a terra, como bem não produzido pelo trabalho.

No entanto, para que a emancipação aconteça, os povos oprimidos dependem uns dos outros, ou seja, precisam construir a intersolidariedade (Ribeiro 2012, p. 303). Todavia, do mesmo modo que a classe revolucionaria não está pronta, mas, em processo de se fazer, a emancipação que abarca toda a humanidade é apenas um projeto, o horizonte para o qual caminham os movimentos sociais populares - entre eles, o movimento camponês.

\section{O Conceito de Emancipação Social no TeCiCampo}

Mesmo tendo como horizonte a emancipação humana na perspectiva de Marx e Engels (1984 p. 25, como citado em Ribeiro 2012, p. 302), e a lógica da emancipação dos excluídos segundo os autores latino americanos acima citados (Freire 1978; 2003, Dussel 2012 \& 
Rebellato 2000 como citado em Ribeiro 2012, pp. 301-302), entendemos que na construção cotidiana deste projeto, é preciso situar esta emancipação de acordo com as possibilidades e desafios que a realidade nos apresenta.

Quando usamos o termo emancipação, nos referimos especificamente ao processo de autorização que os sujeitos se dão para tornarem-se autônomos, serem capazes de fazer escolhas e tomar decisões sobre que valores e crenças desejam compartilhar com que grupos e a que projeto desejam se filiar no cômputo geral da construção social, e como pretendem construir sua ação no mundo. Nosso lugar de fala teórica e metodológica vincula-se ao projeto de democracia redistributiva e do Estado como novíssimo movimento social descrito por Boaventura Santos (2005, pp. 60-61) em seu livro "Reinventar a Democracia". Neste livro o autor compreende o processo democrático na atualidade como um caminho fortemente dependente da participação dos sujeitos na construção política capaz de confrontar e tensionar as posturas fascistas de grupos dominantes que rompem com o contrato social, levando os indivíduos a uma situação social de pré ou póscontratualismo.
$\mathrm{Na}$ situação de pré ou póscontratualismo, os indivíduos são privados de direitos já adquiridos ou que nem chegam a experimentar, sob a tutela de pseudoacordos que, sendo feitos entre desiguais, são impostos pelo mais forte ao mais fraco, sem que este tenha a quem recorrer, uma vez que são juridicamente reconhecidos como legítimos. Numa visão de apropriação patrimonialista do Estado, estas novas correntes fascistas apregoam a imagem de um Estado fraco e ineficiente, que precisa ser encolhido e substituído pela iniciativa privada em suas funções regulatórias. Ironicamente, para produzir sua suposta ineficiência, o Estado necessita de controle e outros elementos só encontrados em um Estado forte e, por isto, este suposto Estado fraco custa tão caro quanto ou mais caro do que o Estado forte, o que penaliza especialmente os trabalhadores que tem de pagar por ele.

A construção de uma nova organização social ou um novo contrato passaria pela participação engajada de grupos sociais em níveis locais e globais que, em luta constante por um Estado democrático em rede, construiriam novos processos de participação dos sujeitos e grupos nas tomadas de decisão mais básicas das suas vidas, criando uma dinâmica de movimento constante em função dos tensionamentos das forças no 
seu interior. A busca desta democracia, na qual os indivíduos participam ativamente das tomadas de decisão, exige que todos tenham acesso, não somente às informações, mas a formas de interpretálas, traduzi-las, estabelecer julgamentos e se posicionar diante de suas consequências, compreender o sentido e a importância da construção política desta sociedade em movimento.

Assim, educar neste contexto, nos leva a construção de um processo onde o sujeito possa ir gradativamente se apropriando de sua educação, fazendo dela autoeducação, acima de tudo. Que este sujeito vá, ao longo do processo pedagógico, vinculando conhecimento e vida, desafios e conquistas a tomadas de posição, atitudes e vitórias à capacidade de lidar com conflitos, resolver problemas e mediar situações contraditórias e que esta postura o leve a se colocar no mundo como ser político.

Isto significa que um processo pedagógico precisa quebrar com o velho paradigma de que o professor ensina e o aluno aprende e começar a se pautar pela questão de que, cada um no seu campo, professor e aluno, são parte desta reinvenção democrática e, como tal, sujeitos ativos que entram no processo com diferentes saberes, expectativas e trajetórias para a construção de um projeto de sociedade, de Estado e de mundo.

No caso dos camponeses, desenvolver esta participação passa pela compreensão de sua própria identidade como sujeitos do campo, neste contexto democrático, e nas contribuições que tem a dar a este projeto, na medida em que resgatam sua identidade para ressignificála nesta nova realidade contemporânea, a partir das necessidades de construção deste novo mundo.

No projeto TeCiCampo, pudemos desenvolver esta intenção mais fortemente na formação dos Educadores/as, tendo neles os principais mediadores dessa construção nas salas de aula, onde o processo emancipatório passou, principalmente, pela construção de ações de afirmação da autoestima, autoconfiança e autonomia dos educandos e pelo seu empoderamento na relação com sua realidade cotidiana imediata.

\section{Perspectivas para a tarefa formação de educadores para alfabetização de adultos}

Nas diversas fases da construção das políticas públicas de EJA no Brasil, podemos notar que a seleção e qualificação dos Educadores/as é um aspecto pouco discutido. De um lado, encontramos a perspectiva assistencialista que traz para 
estes o papel de "voluntários", que assumem o trabalho "por amor à causa", e que podem passar ou não por alguns processos de treinamentos rápidos. De outro lado, há a perspectiva dos militantes que assumem este papel como estratégia política, e que mesclam à sua formação política alguns elementos de formação pedagógica. Mais recentemente, surge a figura do professor das redes de ensino que, tendo sido contratado para assumir na escola o papel de educador de crianças, pode assumir também este papel junto às turmas de jovens e adultos. Isto significa que, em poucos espaços, encontraremos profissionais especialmente qualificados como educadores de adultos, que tenham, de fato, assumido este papel a partir de uma escolha mais profunda, como perspectiva profissional.

Como afirma Soares (2008), em sua pesquisa com os egressos da habilitação de jovens e adultos do curso de Pedagogia da UFMG:

Apesar das conquistas das últimas décadas, que colocam a EJA sob a égide do direito, ainda é corrente a concepção de que esse campo, como adverte Arroyo, é "um 'lote vago', marcado por um caráter compensatório ou supletivo; emergencial e filantrópico, em que basta a 'boa vontade' para atuar"12. Esse tratamento compensatório e assistencialista acarreta, para Ribeiro (2001), um prejuízo para a construção da identidade da EJA como modalidade educativa. (Soares, 2008, pp. 94-95).

No contexto das mais diversas combinações formativas ocorre uma tendência de aligeiramento desta formação, que acaba num aprendizado simples de como utilizar materiais pré-programados e fazer percursos homogêneos para todas as situações. Mesmo no caso em que esta formação ocorra a partir de espaços militantes, as transposições didáticas podem não ser feitas com as devidas reflexões e contextualizações. Sem desqualificar todas as práticas formativas de EJA, refletimos sobre a complexidade dessa formação e o quanto precisa ser amadurecida a partir da experiência e da convivência com os sujeitos e grupos a que se destinam. O aligeiramento implica em uma perda de qualidade do processo, que pode significar uma baixa dos resultados. Segundo Moura (2009):

Os professores que se propõem a ou se impõem a "ensinagem" (Pimenta \& Anastasiou, 2002) de jovens e adultos, em sua maioria não têm a habilitação e a qualificação especial para tal. São quase sempre professores improvisados. Vão contra o princípio de Emília Ferreiro (1993a, 1993b) e Vygotsky (1993, 1991) de que ao alfabetizar, eu amplio a questão para escolarizar, é um ato de conhecimento e, portanto, uma tarefa complexa, demorada e exige competência, habilidades, saberes e,acima de tudo, compromisso de profissionais 
preparados para tal. (Moura, 2009, p. 46).

Não há nenhum outro campo de ensino onde a massificação funcione menos do que na EJA. É preciso compreender o quanto a evasão escolar é uma resposta de determinados perfis de aluno exatamente ao processo de massificação do ensino regular. Podemos notar que, no perfil dos alunos de EJA, não raro encontramos sujeitos de uma inteligência extrema, capazes de lidar com questões complexas e solucionar problemas da vida cotidiana de forma organizada e correta e aprender o que necessita de forma autodidata. No campo da matemática, em especial do cálculo mental, é grande o número de Educandos que, com técnicas próprias, resolvem contas de forma rápida e equiparam suas capacidades de medição com a de instrumentos de precisão. É certo que sua baixa autoestima torna este sujeito às vezes submisso, e às vezes teimoso, mas, sem dúvida, estes não são alunos comuns. Se estão fora da escola, salvo aqueles que dela foram tirados por razões externas à sua vontade, é porque ela não responde às suas necessidades de aprendizagem para a vida e para o trabalho.

A mesma ingenuidade sobre $\mathrm{O}$ sentido do que é trabalhar com estes alunos que não foram mantidos na escola na fase correta e que representam um perfil mais complexo, reflete-se na questão da construção das políticas públicas para formação dos Educadores. Também, nelas ignoram-se as condições que levaram os alunos a estar fora da escola. Algumas políticas funcionam quase como uma espécie de "vamos ver se o aluno se arrependeu e agora dá o braço a torcer”. As políticas desejam números, os Educandos/as desejam conhecimento útil e estimulante que valha o sacrifício que farão de suas horas de descanso, reconhecimento social e qualificação para ascenderem profissionalmente e poderem, de fato, ser reconhecidos socialmente como cidadãos.

Para os sujeitos do campo, acrescenta-se ainda a este cenário a necessidade de reconhecimento de sua realidade específica, de suas lutas e de suas pedagogias. Conforme Arroyo (2012, p. 37): “A presença de outros sujeitos nos remete a coletivos concretos, históricos, classes sociais e os grupos subalternizados, os oprimidos pelas diferentes formas de dominação econômica, política, cultural.” Trazem indagações para as teorias pedagógicas, exigem novas posturas da docência, uma vez que levantam questões desafiantes para a educação popular e escolar. 
Muitas questões encontram-se ainda em debate com vistas à compreensão do que é uma formação de qualidade para o educador de EJA e, neste sentido, as reflexões oriundas das diversas experiências podem contribuir para o entendimento e superação dos preconceitos que cercam este campo da educação. Como aponta Soares (2008) em sua pesquisa:

A falta de profissionalização do educador de EJA é evidenciada, assim, pelos egressos, como o principal problema para uma inserção profissional específica: "eu tenho notícias da existência de muitos lugares com EJA. Local de atuação tem, não sei se o profissional recebe. $\mathrm{Eu}$ acho que dentro disso, a gente tem muito a questão do voluntário na EJA, vão fazer caridade para as pessoas que estão precisando" (Márcia). (Soares, 2008, p. 95).

Neste sentido, a Universidade muito tem a colaborar, especialmente no campo da pesquisa, da formação de Educadores e na aproximação entre saber acadêmico e saber popular. Como afirma Faria (2009):

No enfrentamento dos problemas da qualidade da EJA, há consenso de que as universidades muito têm a construir nos campos de formação e aperfeiçoamento dos Educadores, assessoramento dos professores/pesquisadores sistemas de ensino, elaboração de materiais educativos e na pesquisa educacional. Diversas instituições de ensino superior já vêm oferecendo contribuições à EJA nos âmbitos da pesquisa, assessoria, formação de professores e implementação de projetos. Seu envolvimento com o tema, porém, ainda é marginal, o que se reflete na pesquisa acadêmica, quantitativamente inexpressiva e pouco difundida. (Faria, 2009, pp. 154-155).

O Pronera, como fruto das lutas dos movimentos sociais por políticas públicas de educação do campo, configura-se como um espaço de parceria entre Universidade, Estado e movimento social, que proporciona condições para o desenvolvimento de processos de pesquisa e formação inovadores para a educação, em especial para EJA.

\section{O Pronera}

O Pronera foi construído no diálogo entre assentados de Reforma Agrária, múltiplos movimentos sociais, universidades, órgãos públicos e organizações da sociedade civil, em debates realizados nos encontros e conferências de âmbito nacional que constituíram a chamada Articulação Nacional por uma Educação do Campo. Tem como objetivo "recolocar o rural, e a educação que a ele se vincula, na agenda política do país.” (Lima, 2012, p. 4).

O Pronera representa um importante passo na institucionalização da Educação do Campo como Política Pública, o que pode ser observado na seguinte citação contida em seu Manual de Operações de 2012. 
....o Pronera é o executor das práticas e reflexões teóricas da Educação do Campo,( no âmbito do INCRA), que tem como fundamento a formação humana como condição primordial, e como princípio a possibilidade de todos tornarem-se protagonistas da sua história... (MDA/INCRA, 2012, p. 13).

Tendo se tornado Política Pública em 2010, o Pronera atua a partir de projetos propostos e geridos por universidades e entidades não governamentais em parceria com as associações e movimentos, para serem executados com financiamentos do INCRA por todo o Brasil, assumindo características próprias de acordo com as condições regionais e das Instituições que constroem e executam os projetos. Cabe ressaltar que, embora a alfabetização de jovens e adultos tenha sido a raiz do Pronera, hoje ele atende à educação em diferentes níveis desde o fundamental ao superior pós-graduação.

\section{O contexto do Pronera no Distrito Federal e Entorno}

As ações do Pronera ocorrem diretamente nos assentamentos, acompanhadas por representantes dos assentados que, no geral, participam dos diversos movimentos sociais de agricultores e dos sindicatos e federações ligadas aos trabalhadores rurais que atuam na região. Apesar das diferenças entre estes grupos, a importância da educação e a valorização do Pronera são pontos de convergência para sua ação integrada.

Ao lado de projetos de colonização do período militar, convivem ocupações mais recentes, fruto da atuação da Igreja Católica, de movimentos de trabalhadores rurais sem terra vinculados à Contag, ao MST e a pequenos movimentos locais. (Gasparina, 2000, p.8) como citado em Dansa, 2008, p. 101).

No âmbito do Distrito Federal, o Pronera vincula-se à Superintendência Regional 28 do INCRA (SR28), que atende aos assentamentos do chamado DF e Entorno. Para o INCRA este Entorno abrange municípios do nordeste de Goiás, o Distrito Federal propriamente dito, e o Noroeste de Minas. Este espaço é bastante heterogêneo em termos de acessibilidade e comunicação, o que traz desafios quanto às possibilidades pedagógicas e de formação docente.

Igualmente, a intensa migração que ainda hoje ocorre na região torna seu público heterogêneo, do ponto de vista da sua procedência e mesmo da sua formação educacional. Assim, os assentados, em grande parte migrantes, especialmente da região nordeste de Minas Gerais e também do Sul do país, portam traços culturais, linguísticos e comportamentais diversos. A pluralidade de sentidos e valores é, muitas vezes, responsável por conflitos que tem 
de ser negociados em todos os momentos, não só com relação aos processos pedagógicos, mas, com relação à organização da vida cotidiana.

Os projetos de EJA - Alfabetização e Escolarização $1^{\circ}$ ciclo do Pronera na região do DF e Entorno ocorrem desde 1999 como parceria entre os movimentos sociais locais e a Universidade de Brasília. Dansa, Freitas e Silva Freitas (2012) analisam esta trajetória, mostrando que nela ocorreram quatro projetos que, entre avanços e retrocessos, formaram no total, cerca de 816 Educandos trabalhando com um número entre 38 a 63 assentamentos por vez. Segundo os mesmos autores:

Observa-se, neste processo, uma dificuldade de acesso à organização e sistematização dos dados e reflexões referentes a estes projetos, bem como à identificação de parceiros fora do âmbito dos institutos e movimentos sociais. Este quadro gera uma difícil compreensão da contribuição destes programas para as formulações básicas da Educação do Campo, tanto como ação pedagógica quanto como formulação de Políticas Públicas. (Dansa, Freitas \& Silva Freitas, 2012, p. 225).

\section{O projeto TeCiCampo}

O projeto TeCiCampo visou alfabetizar e escolarizar 600 alunos em 50 salas de aula na distribuição geográfica já mencionada da SR28. O projeto teve a duração de aproximadamente dois anos, desde 2012 até 2014.
Em agosto de 2012 foi realizado o processo seletivo de Monitores/as (estudantes da universidade) Coordenadores/as Locais (representantes dos assentados) e Educadora/es (escolhidas/os dentre pessoas dos assentamentos com qualificação de ensino médio ou superior). Essas categorias de profissionais estão previstas no Manual do Pronera. Nas visitas aos assentamentos foram realizados os primeiros diagnósticos sobre os Educandos. Algumas/uns educadoras/es começaram as aulas experimentalmente, ainda sem remuneração. A orientação / formação de educadoras/es e a produção de material didático de apoio ficou sob responsabilidade de uma equipe pedagógica composta por professores/as da Universidade e outros profissionais vinculados à educação, apoiados pelos Monitores/as e Coordenadores/as Locais.

O trabalho resultou da reflexão coletiva na produção dos materiais sobre o tipo de educação e sua complexidade e teve como referência os PCNs do MEC para EJA, porém, com uma vinculação a uma linha freireana de trabalho, ou seja, a apropriação da leitura e da escrita crítica de mundo traduzida para salas multisseriadas (alfabetização e escolarização $1^{\circ}$ ciclo) e realizada em sintonia com a proposta de Educação do Campo presente no Manual 
de Operações do Pronera. Neste sentido, buscou-se realizar um trabalho de caráter emancipatório, que promovesse a autonomia dos sujeitos envolvidos e a gestão compartilhada do processo.

\section{O TeCiCampo e a formação de Educadores}

Nossa experiência começa na construção do projeto, passa pela organização do plano de trabalho e a complexidade administrativa dos detalhamentos de despesas. Prossegue na organização de um processo pedagógico que inclui construção de um currículo, a formação das/os Educadoras/es e a produção de materiais e estratégias de apoio a esta formação, além do acompanhamento das ações de alfabetização e escolarização no campo. Para isto’, contamos com uma equipe composta de professores/as, estudantes da universidade

(Monitores/as), representantes dos movimentos sociais e sindicatos de trabalhadores rurais (Coordenadores/as Locais), além dos Educadores/as e Educandos/as.

Nesse percurso, buscamos alfabetizar e escolarizar grupos de 8 a 15 alunos em salas multisseriadas nos assentamentos de Reforma Agrária de regiões que incluem a Chapada dos Veadeiros, Flores, Formosa, Padre Bernardo (todos estes, municípios do
Nordeste Goiano), o Distrito Federal e Unaí (no Noroeste Mineiro). Esta complexidade de espaços que caracterizam o que temos denominado de Sertão Mineiro-Goiano (Dansa, 2008, p. 96). Apresenta-se, ao mesmo tempo, como área cultural e ambientalmente similar e diversa, desdobrando-se em paisagens especificas como a chapada, o cerrado em suas diferentes configurações, além de apresentar traços muito peculiares de cultura local, especialmente nos ambientes mais isolados.

Neste espaço, a Reforma Agrária vem se construindo a partir de diferentes grupos étnicos, movimentos sociais de dimensões locais e nacionais, sindicatos, num misto de parcerias e conflitos que vão, a cada momento, dando um matiz diferente à configuração das organizações políticas e sociais desses espaços e modelando um território em disputa. A educação tem sido um dos espaços de encontro entre os movimentos, que permite um debate e ação conjunta e, neste sentido, trabalhamos com ações na área de atuação diversificada de movimentos e sindicatos.

Nesta região, os traços dos assentados variam, sendo os indivíduos, segundo nosso diagnóstico, oriundos de vários estados do Nordeste, Goiás, Minas Gerais, Rio Grande do Sul e outros Estados do Brasil. Essa diversidade significa que 
portam em si relações diferentes com as paisagens, com a cultura local, uns com os outros, com os sentidos que atribuem à sua luta, à sua terra e às razões pelas quais se dirigem neste momento à educação. Todavia, suas razões se encontram no ponto em que associam educação à valorização pessoal e à possibilidade de construir, a partir dela, uma condição de vida melhor, condição esta geralmente associada à empregabilidade ou geração de renda.

$$
\text { Um dos aspectos que }
$$

compreendemos ser muito importante para refletir é como estas pessoas que demandam a educação enxergam seu próprio caminho de emancipação social. Seu discurso e sua prática nos dão pistas de que, apesar de estarem em luta e compreenderem a necessidade de avançar como movimento, resta ainda dentro delas fortes traços dos mitos e crenças que constituem o imaginário social de boa parte dos brasileiros, referente às relações de poder e caracterização do status social vinculados à imagem do opressor e a sua forma de organizar as instituições.

A herança da opressão se reflete no baixo valor que atribuem a si mesmos, a sua forma de falar, de organizar sua vida, de se colocar no mundo como sujeitos coletivos, assim como na resistência que alguns opõem ao próprio movimento, quando este se contrapõe a certas formas instituídas de organização social ou da produção. Também são muito fortes os traços de religiosidade e de obediência cega à autoridade, assim como formas autoritárias de lidar com problemas.

Num primeiro momento, a educação tem, para estes sujeitos, uma configuração bastante tradicional. Suas expectativas apontam para salas de aula com carteiras enfileiradas, quadros negros, cadernos, cópias, ditados e outros instrumentos que caracterizam um modelo bancário de educação, onde morre a criatividade porque não há margem para a invenção e a reinvenção:

... a educação se torna um ato de depositar, em que os estudantes são os depositários e o educador o depositante. Em lugar de comunicarse o educador faz 'comunicados' e depósitos que os Educandos, meras incidências, recebem pacientemente, memorizam e repetem. Eis aí a concepção 'bancária' da educação, em que a única margem de ação que se oferece aos Educandos é a de receberem os depósitos, guardá-los e arquivá-los. (Freire, 1987, p. 33).

Sua imagem é que escola boa é aquela da qual foram expulsos, e que professor bom é aquele que transfere conteúdos e dirige o processo de aprendizagem dos alunos. Sua autoimagem, em especial entre os mais velhos, é a de que são os que ficaram para 
trás, e que agora já são muito velhos para aprender.

Todavia, nesses processos de aprendizagem, quando estimulados, trazem, com um certo orgulho, muitos dos conhecimentos tradicionais de que se utilizam para resolver seus problemas cotidianos e estruturar suas vidas, as histórias que sabem contar, os desafios, charadas, trava-línguas e outras tantas coisas da tradição que acabaram por incorporar. Também na resolução dos problemas para os quais encontraram as soluções próprias, em especial os problemas matemáticos, como contar dinheiro, reconhecer troco, fazer operações de cabeça, medir espaços de formas alternativas ou resolver questões que envolvam uma geometria concreta, sua vivacidade aponta para um lampejo de resgate de sua autoestima. Neste ponto, porém, surgem as resistências das/os educadoras/es em reconhecer estes saberes como legitimas conquistas cognitivas, de forma a aproveitá-los nos processos pedagógicos. A tentativa de romper este círculo de resistência de parte a parte foi dimensão importante do trabalho.

Da mesma forma, entre educadoras/es populares e professoras/es e estudantes da universidade, a barreira e as resistências aconteceram no âmbito da linguagem, seja escrita (nos materiais produzidos), seja na oralidade (durante os processos de formação). Romper este circuito foi um grande desafio que exigiu muitas traduções e retraduções.

Nos processos pedagógicos que se sucederam nos diferentes espaços, pudemos perceber que as resistências às alternativas de uma educação mais emancipatória ora foram percebidas nos Educandos/as, ora nos Educadores/as, ora na própria equipe pedagógica. Foi somente no diálogo extenso que novas possibilidades pedagógicas puderam emergir e se tornar aceitas nos grupos como educação propriamente dita.

Em nosso percurso de trabalho, que segue as linhas do pensamento do educador Paulo Freire, o primeiro momento, o da roda de conversa ou círculo de cultura, passou por um desafio: o de ser compreendido como espaço educativo. A primeira impressão dos Educandos com relação a uma forma mais emancipatória de aprendizagem foi que estavam numa conversa, e não numa aula. A frase chave foi: "quando é que vamos ter aula?"

A diferença entre conversa e aula nem sempre era clara para os Educandos/as. Conversa é debate sobre um tema, onde cada um se expressa, dá sua opinião, debate. Aula é conteúdo sistematizado, trabalhado, conduzido pelo professor, que leva o aluno a sentir que 
aprendeu algo que se aprende na escola, em especial língua materna e matemática.

Também para o educador popular em sua formação, que no nosso caso não é de nível superior, mas, em curso de extensão em processo, esta diferença somente foi ficando clara na medida em que o curso de formação de Educadores/as foi avançando. Nem todos ganharam confiança para abandonar o modelo tradicional. Mesmo para aqueles que se aventuraram, esta trajetória da conversa à aula foi muitas vezes, frustrante, pois, o educador/a não tinha uma base profunda do tema para levá-lo a um nível mais elaborado de reflexão sistematizada, ficando a conversa superficial e, muitas vezes, não havendo conexão com a aprendizagem dos conteúdos escolares que continuavam a vir sob a forma tradicional.

Apesar das inúmeras limitações que vivemos, em função das distâncias e ausências, foi possível notar, em muitas educadores/as, um crescimento na sua forma de construir a ação pedagógica. Se o caminho cognitivo não era suficiente, os vínculos de troca que se criaram entre eles/elas para discutir seus processos, trocar experiências e solucionar questões de sala de aula foram se ampliando ao longo da formação.

O caminho para a conquista dos Educandos/as foi se dando, não só pela dimensão cognitiva, mas, também pela afetividade que a eles/elas passavam a dedicar. A construção da confiança, como em qualquer relação pedagógica, foi por elas/eles tecida na escuta, na compreensão das particularidades dos Educandos/as e na reflexão sobre os questionamentos por nós lançados em relação ao papel pedagógico do erro, a pluralidade linguística $\mathrm{e}$ as relações de poder, o sentido histórico da matemática, o papel orientador do professor, a necessidade de autoeducação e educação permanente.

A entidade professor precisava ser alguém que passasse, acima de tudo, confiança. Não só confiança porque sabia o que ensinava, mas também porque respeitava o outro como ele era, fazia do "erro" um momento do processo de aprendizagem, e não um instrumento de exclusão e poder, e porque apoiava o/a educando/a nos momentos em que ele/ela deixava de acreditar em si mesmo/a, ou tinha de lidar com os conflitos oriundos das questões familiares, inconscientes, de trabalho, etc. Também porque conseguia fazer, de forma tranquila, a relação entre os saberes do/a educando/a e da escola, articulando-os aos temas mais gerais que remetiam aos processos sociais e políticos do contexto em que se encontravam, transformando o que antes era visto pelos Educandos/as como "conversa" em aula. 
Sair desta escola tradicional para um modelo mais Freireano, é sempre um desafio. A confiança no educador/a é um dos elementos fundamentais. A confiança do educador/a em nós, também. A confiança do educador/a em si mesmo, ainda mais. Neste sentido, a formação do educador/a foi um eixo central do trabalho de emancipação dos sujeitos.

As dificuldades encontradas pelos/as Educadores/as para se emanciparem passaram pela sua capacidade de construir o conhecimento de si e para si na mesma lógica proposta para a educação dos Educandos/as. A questão que se coloca é como organizar um processo de formação na perspectiva da autoeducação, quando também nós, como formadores, precisamos passar por estas mesmas etapas de emancipação, não apenas no discurso, mas no cotidiano das ações que desenvolvemos com estes Educadores/as, nos diferentes espaços e processos de formação.

Para nós, como equipe formadora, há ainda o desafio, sempre presente, de romper as barreiras entre as áreas, seja de linguagem, de hierarquização social do conhecimento, epistemológicas e de conexão do conhecimento com a vida, para chegarmos juntos a um ponto que podemos chamar de trajetória de emancipação transdisciplinar, ou seja, olhando para todos os conteúdos juntos descobrir onde queremos chegar e como chegar à vida $\mathrm{e}$ aos Educadores/as e Educandos/as.

\section{Emancipação e organização do trabalho pedagógico}

A arte de construir um processo de formação libertador implica em criar estratégias e mobilizar sensibilidades para que os sujeitos possam se abrir para compreender sua própria relação com os conteúdos, com o processo pedagógico, com o/a educando/a e com a vida, superando seus próprios preconceitos e ampliando sua visão de mundo, passando do pensamento mágico para o pensamento critico sem perder o encantamento que caracteriza o sujeito do campo.

Construir um caminho de sistematização interdisciplinar do conhecimento a partir dos processos vividos, usando como instrumentos as histórias de vida, as trajetórias e territórios percorridos pelos sujeitos, a descoberta dos campos linguísticos e matemáticos como saberes múltiplos (etno-matemática e sociolinguistica), a relação das ciências com os saberes tradicionais, conectando-os à construção de conceitos integradores, como identidade e territorialidade, foram alguns dos caminhos por nós escolhidos para desenvolver estratégias pedagógicas emancipatórias. Parte-se, assim, do concreto para chegar-se ao abstrato, e do 
vivido para pensar o contextual mais amplo, do privado para o público.

$$
\text { Emancipação passa por }
$$

compreender, no nosso cotidiano, como se manifesta a lógica autoritária de construção do poder do opressor em cada uma das pequenas vivências do nosso dia-a-dia para pensar uma lógica democrática. Valorizar as lutas e movimentos sociais como forma de construção de processos de auto-gestão e cooperação entre iguais, para uma nova forma de participação nas tomadas de decisão nos espaços públicos. A emancipação passa ainda por valorizar as políticas públicas como instrumentos de luta que possibilitem a transformação das instituições, no caso educação, agricultura, uso e posse da terra etc.

\section{As interações sociais como espaço emancipatório}

Ao final de quase dois anos de trabalho, percebemos que foi possível construir um espaço de diálogo e prática sobre a EJA e a educação que resultou em processos de emancipação dos diversos sujeitos envolvidos.

Para os estudantes da Universidade, este processo possibilitou um espaço de vivências concretas do seu fazer educativo, amadurecimento das reflexões teóricas e práticas sobre os sujeitos e relações educativas, a construção de currículo, métodos e materiais pedagógicos, além do desenvolvimento da capacidade de pesquisar, realizar diagnósticos e aprender a expressar academicamente esta reflexão. $\mathrm{O}$ exercício do ir e vir da linguagem acadêmica para a linguagem popular e vice versa foi extremamente rico, e possibilitou ao grupo momentos também ricos de construção da socialização do saber e de diálogo entre o saber popular e acadêmico, linguagem oral e escrita, além de um enriquecimento do universo antropológico e sociopolítico de todos os sujeitos participantes.

Em seu trabalho final de curso, Costa (2013), à época monitor do projeto TeCiCampo, refletindo sobre o estudo que realizou com educadoras, nos remete ao enunciado de Dewey de que "educação é vida" ao dizer que:

Perceber o envolvimento de Educandos e Educadores que juntos descobrem um novo universo antes inimaginável, onde a educação surge como alicerce para várias conquistas do dia-a-dia, como uma mera assinatura num documento, a autonomia de pegar uma condução sozinho, conseguir tirar a tão sonhada carteira de habilitação, ler uma notícia e poder registrar a suas histórias sem o auxilio de terceiros. Para muitos que tiveram a oportunidade de ingressar desde crianças num processo educativo que lhes proporcionou estes instrumentos pode parecer algo muito singelo, porém a emancipação do mundo que a aquisição do domínio da forma escrita traz é imensurável para 
aqueles que aspiram novos horizontes. (Costa, 2013, p. 64).

Isto se reflete na participação direta dos estudantes na construção dos materiais pedagógicos, das oficinas de língua materna e matemática, na participação de eventos com produção de artigos, banners, folders, monografias, materiais para diálogo com as organizações governamentais participantes do processo, bem como na ampliação de seu universo na convivência direta com os/as Educandos/as, Educadores/as, Coordenadores/as Locais, sujeitos do campo em geral. Tudo isso ofereceu aos estudantes condições para a aprendizagem do processo democrático na educação a partir do diálogo, da elaboração de suas próprias hipóteses sobre as situações e uso da criatividade para buscar soluções junto com Educadoras/es, Educandos/as, coordenadores/as e equipe de forma geral, para os problemas vivenciados na construção do projeto, caracterizando um vínculo dialógico entre a Universidade e a comunidade, por meio do ensino, pesquisa, extensão. Como afirma Faria (2009):

As universidades e os centros de pesquisa e de formação assumem, neste momento, espaço fértil para desenvolver pesquisas, reflexão teórica e práxis. Espaço este, de fomentação, socialização e engajamento. Segundo Arroyo (2005, p. 20), "este pode ser um ponto promissor na reconfiguração da EJA: as universidades em suas funções de ensino, pesquisa e extensão se voltam para a educação de jovens e adultos ... Neste contexto, a Universidade desempenha um papel significativo dentro da sociedade através da indissociabilidade entre ensino, pesquisa e extensão. Esses pilares são importantíssimos para a permanente produção científica, o estabelecimento de elos e a intensificação de diálogo entre o contexto acadêmico e os diversos segmentos que constituem a sociedade. (Faria, 2009, p. 3).

Em relação a interações dos Coordenadores/as Locais com o projeto, percebeu-se que, à medida que o processo avançou, houve um envolvimento crescente, além de uma maior conscientização do seu papel, apoiando, estimulando e fiscalizando os processos educativos, relatando os casos de salas de aula com problemas, buscando substitutos imediatamente quando da desistência de algum educador/a e apoiando a coordenação do projeto nos processos necessários, como a mediação com 0 INCRA e outros parceiros. Houve ainda maior autonomia na tomada de decisões e no diálogo com os demais membros da equipe, em especial os Monitores/as, com quem trabalharam mais diretamente. Conseguiram criar uma atmosfera de confiança por parte dos Educadores/as, que os reconheciam como lideranças e mediadores no processo de auxílio para o grupo resolver diversos problemas, bem 
como de estimuladores da motivação para aprender, ensinar e cumprir os compromissos.

Notou-se, ainda, nestes Coordenadores/as Locais um despertar da vontade de estudar e avançar que levou alguns deles a buscarem cursos superiores ou outras formas de complementação dos seus estudos enquanto inseridos na experiência do TeCiCampo, bem como assumir seu papel como Educadores/as e mobilizadores em momentos de formação dos sujeitos do processo .

$\mathrm{Da}$ parte das/os educadoras/es, notou-se também que, à medida que o processo avançou, foi aumentando o grau de autonomia e o interesse em estudar, tendo algumas buscado cursos superiores em modalidades à distância ou a Licenciatura em Educação do Campo.

O Pronera em minha vida (...) trouxe uma enorme experiência, bagagens de conhecimento. E eu cresci como pessoa, em experiência e em conhecimento. Hoje curso a faculdade de Pedagogia, graças à iniciativa do Pronera. (Educadora do TeCiCampo, 2014).

O nível de interação e trocas de experiências entre elas/eles também cresceu, e sua relação com suas comunidades e outros parceiros para buscar materiais, sejam para a sala de aula, seja para a preparação de aulas, também se intensificou.
Consegui materiais com a Secretaria de Educação sob a condição de devolver ao final do Projeto. Nas escolas do assentamento vizinho consegui livros pedagógicos e didáticos, especialmente os que abrangem o método Paulo Freire (...) com o ensino de jovens e adultos. (Educadora do TeCiCampo, 2014).

Sua capacidade de compreensão de como trabalhar num processo de salas multisseriadas também foi outro aspecto que avançou ao longo do projeto. Sua relação com os Educandos/as também foise solidificando, em particular entre aqueles/as que permaneceram desde o inicio e que se envolveram mais profundamente com o projeto. Para estes/as educadores/as, o processo de formação foi considerado relevante $e$ produtor de mudanças no seu olhar.

O que me ajudou muito mesmo foram os cursos de formação (...) onde eu tiro minhas dúvidas e aprendo a lidar com as dificuldades. No curso de capacitação aprendi outras formas de ensinar e alfabetizar os alunos, (...) que não basta somente eles aprenderem a ler e escrever, mas a terem conhecimento de seus direitos $e$ a serem cidadãos. (Educadora do TeCiCampo, 2014).

Da parte dos Educandos/as, nota-se que o nível de credibilidade em relação ao projeto foi crescendo na medida que as promessas, como a de entrega dos óculos, continuidade das ações, remuneração correta das educadoras/es puderam ser 
cumpridas. Uma fala de educadora relata: "A maior superação para eles foi a vinda dos óculos. Uma vitória!” E diz ainda um coordenador local: "O bom neste projeto do Pronera é que contribuiu para o povo ter (dar) credibilidade."

Com relação aos Educandos/as, também pode-se ver que muitos conseguiram dar o salto para a alfabetização e, naqueles que atingiram um patamar de escolarização, a demanda foi pela certificação e pela continuidade dos estudos. Como relata uma educadora, quando perguntada sobre as expectativas dos alunos: "Para uns, ler e escrever. Para outros, o certificado de $1^{o}$ ao $5^{o}$ ano." (Educadora do TeCiCampo).

Também podemos perceber que diversos Educandos expressaram sua satisfação por terem atingido suas expectativas iniciais, como assinar o nome, ler placas, ler contratos, tirar carteira de motorista e estar melhor qualificados para o acesso às informações do trabalho.

Do ponto de vista acadêmico e de gestão, o grupo cresceu e aumentou a coesão da equipe, que desenvolveu vínculos com o trabalho e buscou se organizar em diversos sentidos, inclusive em termos de produção acadêmica: três cadernos didáticos de apoio aos Educadores/as, duas monografias; um artigo para congresso, dois capítulos de livro, um livro de relatos do projeto, além de um vídeo / documentário.

Para os professores/as da Universidade, a prática dialógica foi um elemento emancipatório, na medida que funcionou como ferramenta de construção coletiva para articular diferentes conhecimentos acadêmicos, saber popular e tradicional e integração interdisciplinar na construção de materiais pedagógicos e na formação.

Por outro lado, a compreensão das demandas educacionais específicas dos camponeses nos fez mergulhar no universo desses sujeitos, para encontrar caminhos que possibilitassem a formação dos Educadores/as, de forma a capacitá-los para atender a essas demandas. Um exemplo desta articulação pode ser encontrado em Oliveira (2013) que, no seu TCC sobre a realidade do Pronera na região de Padre Bernardo, analisou o depoimento dos Educandos/as à luz das ideias de comunidade desenvolvidas por Martin Buber.

\section{Desafios enfrentados na construção do projeto emancipatório}

A realidade nos colocou desafios de diferentes ordens. Houve muitas substituições de educadores, fechamento de salas. As principais razões para este cenário foram as saídas do assentamento, 
arranjar outro trabalho, gravidez, atraso dos pagamentos, problemas com o movimento social, a associação dos assentamentos etc, alta evasão dos Educandos/as. Cerca de 27 educadores/as dentre 50 passaram por alguma situação relativa a esta instabilidade. Foi necessário o fechamento de 15 salas, em momentos diversos do processo, por ausência de alguém para assumir o papel de educador/a. Apesar do remanejamento dos educandos/as houve alguma evasão.

Com relação aos educandos/as, a dificuldade maior foi manter a frequência nas atividades e evitar a evasão. A partir das nossas observações e coletas de dados pudemos identificar como principais motores desta instabilidade: as dificuldades visuais: "O que mata a gente mais é essa falta de óculos" (Educando do TeCiCampo, 2014); o cansaço dos alunos trabalhadores; a necessidade de cuidar do trabalho e da família; questões relativas à indisposição de maridos ou esposas com o estudo do parceiro; doenças e necessidade de tratamento fora dos assentamentos; mudanças de moradia, em especial nos acampamentos; grandes distâncias das salas de aula até a casa: "A mudança da sala de aula para minha humilde residência. Ficou mais perto e os alunos passaram a frequentar com mais vontade de estudar." (Educadora do TeCiCampo,
2014); rotatividade de Educadores/as; insegurança no processo de aprendizagem, e até mesmo o medo dos exames de qualificação.

Do ponto de vista da gestão, a organização compartilhada dos processos nos fez compreender a importância de construir diálogo interinstitucional junto com todos os envolvolvidos, para atender as demandas jurídico administrativas e realizar os processos pedagógicos, simultaneamente, e tornar mais sustentável os processos de gestão.

\section{Considerações finais}

Consideramos que contribuímos com os objetivos do projeto de desenvolver as ações numa perspectiva emancipatória nos seguintes aspectos: a construção colegiada dos processos, inclusive das tomadas de decisão; o trabalho de campo em equipe, envolvendo sempre a parceria entre monitores, estudantes da universidade e coordenadores/as locais, representantes dos movimentos sociais e educadoras/es; ênfase na formação das/os educadoras/es nas dimensões emancipatórias da educação, como respeito aos educandos, aos saberes de que eram portadores; superar barreiras próprias dos educadores/as e dos educandos/as provenientes da educação bancária, experimentando novos formatos de 
educação; expandir o projeto para além da sala de aula, por meio da realização de oficinas com temáticas pertinentes a vida e aos direitos dos educandos (saúde, trabalho e sustentabilidade); autonomia reflexiva dos estudantes da universidade, que se debruçaram sobre temáticas do projeto ainda durante o percurso, possibilitando um olhar mais abrangente que ajudou na construção da trajetória, a partir de TCCs, escrita coletiva de artigos e textos, livros e vídeos. O próprio processo levou aos educandos/as a possibilidade de romper com a dependência de intermediários, criando novas habilidades de negociação da produção. Conforme relatou um estudante a um programa radiofônico, após aprender os rudimentos da leitura e da matemática, ele foi capaz de ir para internet e encontrar e processar informações sobre produtos e preços, que mudaram sua relação com os intermediários, fortalecendo sua capacidade de negociação dos preços da produção.

Isso nos permite pensar na educação de adultos como um campo específico, onde o respeito à motivação dos sujeitos está muito ligado à necessidade de resolver problemas imediatos. Se, por um lado, isso por si só não garante um salto emancipatório do ponto de vista político social, constitui-se como uma base importante para este salto, pois implica em que o sujeito transformou sua condição de subordinado aos processos e condições externas diante dos quais se sentia impotente para uma posição confiante para a realização do diálogo, que agora se constitui a partir de parâmetros mais objetivos, uma vez que ele também tem acesso e faz uso das informações que o empoderam, criando novos espaços relacionais. Podemos afirmar que estes sujeitos hoje se autorizam a romper com a dependência e com a dominação a que estavam antes sujeitos, enquanto seres fora da sociedade letrada. Muito há ainda que caminhar para garantir que esta emancipação se torne participação na construção democrática .

Também a volta aos estudos dos educadores/as e coordenadores/as locais foi um passo importante na construção desse processo emancipatório. Faz parte da educação despertar nas pessoas a consciência da incompletude do saber.

Em relação aos professores/as da Universidade, houve uma ampliação das leituras do mundo e do respeito aos diferentes sujeitos e saberes, bem como a extrapolação dessas experiências para a sala de aula, alterando pontos de vista da relação com a natureza, com os movimentos sociais, criando vínculos e competências de diálogo institucional para 
atender às demandas dos movimentos sociais.

Para completar este processo, os sujeitos que chegaram ao final e obtiveram sua certificação tiveram que realizar, durante este percurso, uma série de superações de ordem interna, como: enfrentar seus fantasmas e opressores internalizados; as dificuldades impostas pelo corpo, como a visão, o cansaço, as doenças eventuais; a dificuldade de compreensão das linguagens e novas formas de pensar diferentes das habituais, que os obrigaram a reconstruir ou traduzir suas bases conceituais para passar da lógica oral para a escrita, do concreto para o abstrato. Também houve superações de ordem externa, como: as distâncias percorridas; lugares de difícil acesso; precariedades das condições materiais e dificuldades de conciliar trabalho e estudo. Tudo isso possibilitou um fortalecimento da vontade do sujeito e da importância dada aos processos vivenciados, que muitas vezes tiveram que ser negociados com as famílias, que ao final foram festejálos na formatura. Com esse esforço, mostraram para as pessoas que a mudança é possível, passando da condição de dependentes à de exemplo de luta. Isso também pode ser considerado como emancipação.

\section{Referências}

Arroyo M. (2012). Outros sujeitos, outras pedagogias. Petrópolis: Editora Vozes.

Caldart, R., Pereira, I., Alentejano, P., \& Frigotto, G. (2012). Dicionário de Educação do Campo. Rio de Janeiro, São Paulo: Escola Politécnica de Saúde Joaquim Venâncio, Expressão Popular.

Costa, A. (2013). Um Estudo do Processo Formativo dos/as Educadores/as do Projeto Tecendo a Cidadania no Campo. (Monografia de Graduação). Universidade de Brasília.

Dansa, C. (2008). Educação do Campo e Desenvolvimento Sustentável na região do Sertão Mineiro Goiano. (Tese de Doutorado). Universidade de Brasília, Brasília.

Dansa, C., Freitas, H., \& Silva Freitas, M. C. (2012). Políticas Públicas de Educação do Campo: a contribuição da Universidade de Brasília. In Cunha, C., Sousa, J. V., \& Silva, M. A. (Orgs.). Avaliação de políticas públicas de educação. Faculdade de Educação/Universidade de Brasília: Líber Livro.

Faria, E. (2009). O percurso formativo dos professores/pesquisadores da EJA na contemporaneidade. Práxis Educacional, 5(7), 151-164.

Freire, P. (1987). Pedagogia do oprimido. Ed. Rio de Janeiro, Paz e terra.

Lima, N. (2012). Percursos educativos e ações do MST: a EJA do campo no assentamento Bernardo Marin II. In $I$ Seminário Internacional e I Fórum de Educação do Campo da Região Sul do Brasil: Campo e cidade em busca de caminhos comuns. Disponível em: http://docplayer.com.br/8435063-

Percursos-educativos-e-acoes-do-mst-a- 
eja-do-campo-no-assentamento-bernardomarin-ii-russas-ceara.html.

Ministério do Desenvolvimento Agrário/Instituto Nacional de Colonização e Reforma Agrária. (2011). Manual de Operações do Pronera. Brasília.

Moura, T. M. M. (2009). Formação de Educadores de Jovens e Adultos: realidade, desafios e perspectivas atuais. Práxis Educacional, 5(7), 45-72.

Oliveira, M. (2013). A Educação de jovens $e$ adultos do campo do Distrito Federal e Entorno no contexto do Programa Nacional de Educação na Reforma Agrária - PRONERA: uma análise do passado, um apontamento para o futuro. (Monografia de Graduação). Universidade de Brasília.

Ribeiro, M. (2012). Emancipação versus cidadania. In Caldart, R. Pereira, I., Alentejano, P., \& Frigotto, G. (Orgs.). Dicionário de Educação do Campo. (pp. 299-304). Rio de Janeiro, São Paulo: Escola Politécnica de Saúde Joaquim Venâncio, Expressão Popular.

- (2012) Educação do Campo: embate entre movimento camponês e estado. Educação em Revista, 28(1), 459490.

Santos, B. (2002). Reinventar a democracia. Lisboa: Gradiva.

Soares, L. (2008). O educador de jovens e adultos e sua formação. Educ. rev. (47). Disponível em: http://www.scielo.br/scielo.php?script=sci _arttext\&pid=S0102-46982008000100005. Acesso em 04/10/2016.

MST. Documento Básico. 1997.

Touraine, A. (1983). Palavra e sangue. Campinas: UNICAMP.
Thompson, E. P. (1981). Miséria da teoria. São Paulo: Zahar.

Normais Gerais do MST. (1989). São Paulo.

Recebido em: 05/10/2016 Aprovado em: 19/11/2016 Publicado em: 13/12/2016

\footnotetext{
Como citar este artigo / How to cite this article / Como citar este artículo:

APA:

Freitas, M. C. S., Dansa, C. V. A., \& Moreira, J. M. C. (2016). Pronera no Sertão Mineiro Goiano: Reflexões sobre emancipação social e Educação do Campo. Rev. Bras. Educ. Camp., 1(2), 204-230.

\section{ABNT:}

FREITAS, M. C. S.; DANSA, C. V. A.; MOREIRA, J. M. C. Pronera no Sertão Mineiro Goiano: Reflexões sobre emancipação social e Educação do Campo. Rev. Bras. Educ. Camp., Tocantinópolis, v. 1, n. 2, p. 204-230, 2016.
} 